\title{
Tutkat hyönteismigraatioiden valvontaan
}

\author{
Matti Leskinen ${ }^{1)}$, Pirkko Pylkkö ${ }^{2)}$, Irmeli Markkula ${ }^{3)}$, Kari Tiilikkala \\ 1) \\ Helsingin yliopisto, PL 64, 00014 HELSINGIN YLIOPISTO \\ 2) \\ Ilmatieteen laitos, PL 503, 00101 HELSINKI \\ Maa- ja elintarviketalouden tutkimuskeskus, 31600 JOKIOINEN
}

\section{Tiivistelmä}

Säätutkilla kartoitetaan sadealueita. Ilmassa lentävät hyönteiset aiheuttavat sateiden ja satavien pilvien ohella merkittävimmän kaiun kesäaikaan säätutkissa. Koska tutkan mittauksessa käytännöllinen alin korkeus on sadan metrin luokkaa, hyönteiset ovat tällöin niin korkealla että niitä voidaan yleensä pitää vaeltajina. Vaeltavat hyönteiset nousevat tarkoituksellisesti tällaisille korkeuksille, kun taas muusta syystä liikkeellä olevat yksilöt pysyttäytyvät alhaalla, jossa ne voivat omalla lentonopeudellaan ylittää ilmanvirtausnopeuden ja pystyvät pääsemään kohteeseensa. Säätutkilla hyönteisten aiheuttama kaikukerros ulottuu tavallisesti noin +5 asteen lämpötilaan saakka, jolloin noin +25 asteen pintalämpötilassa kauniina kesäpäivänä kaikukerros voi olla noin kahden kilometrin paksuinen.

Hyönteismigraatiolla voidaan tarkoittaa hyvin erilaisia yksilöiden liikkeitä, joilla on merkitystä lajin populaatioille. Suomessa migraatioihin liittyviä tutkimuksia on tehty paljon toisaalta perhosten ja toisaalta tuhohyönteisten osalta. Metapopulaatioiden tutkimuksessa migraatio on myös keskeinen tekijä. Hyönteisten vaellusten tarkkailussa kiinnostuksen kohteena ovat olleet erityisesti immigraatiot, jotka tuovat tarkastellulle alueelle yksilöitä. Immigraation merkitys korostuu tuhohyönteisten vaikutusten arvioinnissa, koska yleensä ennustusmenetelmät populaatioiden kehittymisestä perustuvat havaintoihin paikallisesta populaatiosta.

Erityisesti Helsingin yliopiston säätutkan mittauksia on viime kahdenkymmenen vuoden kuluessa käytetty lähinnä kirvojen ja perhosten immigraatioiden tutkimuksessa. Tämän tutkan sijainti Suomenlahden rannikon tuntumassa onkin tehnyt mahdolliseksi erottaa meren yli tulevat immigraatiot lyhytkestoisemmista paikallisista vaelluksista. Toisaalta taas Ilmatieteen laitoksen säätutkaverkosto kattaa varsinkin Etelä-Suomen kesäisten sateiden osalta varsin hyvin, jolloin myös hyönteisvaellusten seurantaa voidaan tehdä koko alueella. Vuoden 2004 lopulla Helsingin yliopiston rakennuksen katolle Kumpulan yliopistoalueella asennettiin uuden säätutkan antenni. Tämä Vaisala Oyj:n rakentama tutka on Suomen ensimmäinen polarimetrinen säätutka.

Polarisaatiosäätutkalla kyetään aikaisempaa paremmin erottamaan hyönteiset muista kaiun aiheuttajista ja lisäksi on mahdollista saada lisää tietoa havaittavien hyönteisten lajistosta ja käyttäytymisestä ilmavirtauksissa. Tämän tutkan käyttömahdollisuuksia ja yleensä vastaavanlaisten järjestelmien hyödyntämistä tutkitaan hankkeessa "Polarisaatiotutkan monitieteelliset sovellukset". Yksi alue tässä tutkimuksessa on kehittää tuhohyönteisten vaellusten ennustusmalli. Tässä osuudessa ovat mukana Helsingin yliopisto, Ilmatieteen laitos ja Maa- ja elintarviketalouden tutkimuskeskus. Säätutkilla ja erityisesti käytössä olevalla uudella polarisaatiotutkalla hyönteisvaelluksia pyritään seuraamaan tämän ennustusmallin toiminnan varmistamiseksi. Samaan aikaan tehostetulla hyönteisten pyydystyksellä selvitetään vaellusten saapumista maastoon.

Asiasanat: säätutka, hyönteismigraatio, vaellus, polarisaatiotutka, ennustusmalli 


\section{Johdanto}

Ilmassa olevat hyönteiset ovat mikroaaltoalueen tutkilla sangen hyvin havaittavissa (Riley 1985, Leskinen 1990). Hyönteisten vaellusta on seurattu maailmalla sekä hyönteistieteellisillä tutkilla että säätutkilla. Käytännössä hyönteistieteelliset tutkat toimivat useimmiten $3 \mathrm{~cm}$ ja säätutkat 3,5 tai $10 \mathrm{~cm}$ aallonpituudella. Nämä eri tarkoituksiin suunnitellut tutkalaitteistot ovat periaatteiltaan samankaltaisia, mutta niiden kaikujen tarkastelumenetelmissä on eroja. Käytännössä eri syistä johtuen säätutkat ovat yleensä herkempiä havaitsemaan hyönteisten aiheuttamaa kaikua, kun taas hyönteistieteellisen tutkan avulla kyetään määrittämään tarkemmin kaikua aiheuttavien hyönteisten lajistoa. Hyönteistieteelliset tutkat ovat hyvin harvinaisia, mutta säätutkia on olemassa verkostoina sateen eli sään kaukokartoitusta varten.

Tuhohyönteisten esiintymisen ennustaminen perustuu havaintoihin paikallisesta kannasta ja mahdollisesti myös paikallisen sään vaikutus kannan kehittymiseen voidaan ottaa huomioon. Tuomikirvan esiintymisen ennustaminen on yksi esimerkki tällaisesta ennustamisesta ja vaelluksen osuutta voidaan arvioida pyydyshavaintojen perusteella (Kurppa 1989). Hyönteismigraatioiden valvonta voi perustua havaintoihin pyydyksissä tai kasvustoissa. Tällainen havainnointi on sinänsä helppoa, mutta laajalla alueella työlästä ja vaellusta ei usein havaita riittävän ajoissa torjuntatoimia varten. Euroopassa on toiminnassa imurysien verkosto, jossa useassa paikassa mitataan $12 \mathrm{~m}$ korkeudella havaittuja hyönteisiä. Suomessa tällainen pyydys on mm. Viikin yliopistoalueella ja kasvukauden aikana näytteet kerätään 2 kertaa viikossa. Merkittävää hyönteisten vaellusten havainnointia tekevät perhostutkijat, Suomessa jopa kattavimmin maailmassa, mutta perhosrysissäkin keruujakson kesto on tavallisesti useita vuorokausia.

Säätutkien käyttöä hyönteisvaelluksen valvonnassa on pidetty yhtenä mahdollisuutena tehostaa vaelluksen havaitsemista, kun ilmassa vaeltavat hyönteiset huomataan jo ennen kuin nämä laskeutuvat lisääntymisalueille vaelluksen päätteeksi. Käytännössä säätutkat ovat myös jatkuvasti tarkkailemassa säätä, jolloin havaintoja saadaan jatkuvasti laajalta alueelta. Säätutkia käytetään pääasiallisesti lyhytaikaisen säänennustuksen apuna ja laskettaessa alueellista sadantaa halutuilta ajanjaksoilta. Suomessa kaikki säätutkat ovat Doppler-tutkia, joilla voidaan selvittää myös virtaus. Tutkien tietoja voidaan käyttää hyödyksi myös numeerisissa säänennustusmalleissa, joihin olennaisesti kaikki muutamaa tuntia pidemmälle ulottuvat säänennusteet perustuvat.

Isoista hyönteisistä saadun kaiun voimakkuuden havaittiin vaihtelevan hyönteisen siivenlyönnin tahdissa jo 1960-luvulla tehdyissä säätutkamittauksissa (Glover ym. 1966) ja tutkahyönteistiede saikin alkunsa pian tämän jälkeen (Schaefer 1976). Kaikille hyönteisille ominainen piirre tutkakaiussa on kaiun voimakkuuden riippuminen hyönteisen pitkulaisen ruumiin asennosta säteilyn polarisaatiosuuntaan nähden. Tutkakaiku on voimakkaampi, kun säteilyn polarisaatiosuunta on ruumiin suuntainen eikä tätä vastaan kohtisuorassa suunnassa (Riley 1985). Säätutkissa on käytetty vaakapolaroitua säteilyä ja tällöin kaiku on voimakkainta kun hyönteisen kylki on kohti tutkaa. Tähän perustuen on voitu todeta vaeltavien hyönteisten asettumista yhdensuuntaisesti (Nieminen ym. 2000).

Polarisaatiotutkalla mitataan erilailla polaroidun säteilyn kaiun ominaisuuksia. Hyönteistieteellisissä tutkissa on käytetty säteilyn lineaarisen polarisaatiosuunnan nopeaa pyörittämistä ylöspäin suunnatussa antennissa. Tutkan yli lentävä hyönteinen on havaittavissa vain muutaman sekunnin ajan, mutta tämän mittausjärjestelyn avulla ehditään kuitenkin mittaamaan kaiun voimakkuuden vaihtelun riippuvuus polarisaatiosuunnasta ja sitä kautta määrittää hyönteisen ruumiin suunta (Chapman ym. 2002). Säätutkissa kiinnostus on kohdistunut eroihin, joita havaitaan vaaka- ja pystypolaroidun säteilyn välillä. Havaittuja vaikutuksia käytetään sateen olomuodon tunnistamiseen sekä sateen voimakkuuden mittaamisen tarkentamiseen, mutta hyönteisten aiheuttamien kaikujen osalta on tarkasteltu myös vaeltajien lentoon liittyviä seikkoja (Achtemeier 1991). Vaikka viime vuosikymmenen aikana kehitetty hyönteistieteellinen tutka antaa jo paljon tietoa havaitusta hyönteisestä pelkän kaiun perusteella, niin käytännössä vaelluslajiston selvittämiseen tarvitaan edelleen maanpinnalla tehtäviä havaintoja.

Migraation eli vaelluksen ennustaminen voi perustua hyvään tietoon paikallisista populaatioista, arvioon näiden kehittymisestä sekä säänennustukseen sopivana vaellusajanjaksona. Käytännössä pitkiä vaelluksia hyvissä tuulissa tekevien lajien tulon ennustaminen on vaikeaa, kun kuitenkin populaatiotie- 
toja ei ole kattavasti olemassa ja myös mahdollinen lähtöalue on laaja. Tutkimushankkeessa "Polarisaatiotutkan monitieteelliset sovellukset", POMO, on yhtenä osana kehittää tuhohyönteisten vaellusten ennustemalli. Tätä tehdään Maa- ja elintarviketalouden tutkimuskeskuksen (MTT), Ilmatieteen laitoksen sekä Helsingin yliopiston yhteistyönä. Helsingin yliopiston katolla Kumpulassa olevaa uutta polarisaatiosäätutkaa sekä muita säätutkia käytetään mallin kehittämisessä vaellusten seuraamisessa. Lisäksi tutkia ja muita kaukokartoitusmenetelmiä on kaavailtu mukaan ennustemalliin päivittämään vaellustilannetta. Hyönteispyydyksiä sijoitetaan poikkeuksellisen runsaasti varsinkin polarisaatiosäätutkan mittausalueelle maastoon tulevien vaeltajien selvittämiseksi.

\section{Säätutkat Suomessa ja hyönteisten vaellukset}

Kirkkaan ilman kaikuja alettiin tutkia säätutkalla Helsingin yliopistossa 1980-luvulla Suomen ensimmäisen Doppler-säätutkan osoittaessa nämä hyödyllisiksi meteorologiassa (Puhakka \& Saarikivi 1986). Koska kaiut tällä tutkalla arvioitiin lähinnä hyönteisten aiheuttamiksi, alettiin samalla myös tarkastella mitä tutkakaiut kertovat hyönteisten vaelluksista (Leskinen 1990). Helsingin yliopiston säätutkan tietoja on tämän jälkeen käytetty etenkin kirvojen ja perhosten vaellusten tarkastelussa (Mikkola 1996a, 1996b ja 2003, Nieminen ym. 2000). Ilmatieteen laitoksen tutkaverkostoa on myös käytetty hyväksi hyönteisten joukkovaellusten tarkasteluissa (Tiilikkala ym. 1996, Mikkola 1996b). Kirvojen ja kaalikoiden vaelluksiin liittyneitä tutkahavaintoja on joitakin kertoja välittömästi käytetty hyväksi tuhohyönteisvaroituksissa. Katsauksia säätutkan käytöstä hyönteisvaellusten havainnoinnista on esitetty tietokirjoissakin (Leskinen 1998, Mikkola \& Leskinen 1998 ja Leskinen 2005).

Tällä hetkellä Helsingin yliopistossa on käytössä kaksi Doppler-säätutkaa, joista uudempi Kumpulan alueella oleva tutka on vuoden 2004 lopulla Vaisala Oyj:n rakentama polarisaatiotutka. Ilmatieteen laitoksen tutkaverkostossa on kahdeksan Doppler-säätutkaa ja Etelä-Suomessa näiden välimatka toisistaan on $200 \mathrm{~km}$ luokkaa. Hyönteisten aiheuttaman kaiun suurin havaintoetäisyys riippuu hyönteisten koosta, yksilötiheydestä sekä lentokorkeudesta. Tutkamittauksessa kaikuteho heikkenee etäisyyden kasvaessa ja samalla havaittava ilmatilavuus nousee ylemmäs maanpinnan kaarevuuden takia. Lisäksi hyönteisten määrä tavallisesti pienenee ylemmäksi mentäessä. Nämä kaikki tekijät aiheuttavat hyönteisten vaelluksen havaittavuuden heikkenemistä etäisyyden kasvaessa. Hyönteisiin liittyvä kaiku havaitaan kauniilla kesäsäällä silti usein 100 km etäisyydeltä saakka.

Yleensä voimakkain hyönteisten aiheuttama kaiku havaitaan lähellä maanpintaa. Ylempänä hyönteisiä tavataan silti sangen yhtenäisenä kaikukerroksena noin +5 asteen lämpötilaan saakka. Kesäpäivänä pinnan lämpö siirtyy ilmaan joka harvenee ja nousee ilman pyörteinä ylemmäksi. Ylempänä ilmanpaine on alempi ja kohoava ilma jäähtyy. Hyvän sekoittumisen myötä syntyy ns. rajakerros, jossa ilmakehän lämpötila laskee noin asteen sadan metrin nousussa. Tämä myös nähdään hyönteiskaiussa jokseenkin niin, että kun pinnassa ollaan hellelukeman kynnyksellä +25 asteessa, niin kaikukerros ulottuu kahden kilometrin korkeuden vaiheille.

Hyönteisten aiheuttamien säätutkakaikujen vuorokautisessa vaihtelussa Suomessa havaitaan samoja piirteitä kuin muuallakin maailmassa. Edellä kuvatun kaltainen päivätilanne syntyy aamupäivällä hyönteisten määrän kasvaessa. Iltaa kohden hyönteiset alkavat yleensä vähetä ja kaikukerros muuttuu matalammaksi, vaikka samalla rajakerroksen korkeus jopa suurenee edelleen. Auringonlaskun aikaan havaitaan tavallisesti tunnin ajan kaiun voimistuminen puolen kilometrin paksuisessa kerroksessa, kun ilmeisen pieniä hyönteisiä nousee runsaasti ilmaan. Sen jälkeen saatetaan havaita runsaammin isoja hyönteisiä tasaisemmin paljon paksummassa ilmakerroksessa. Yön aikana hyönteiset vähenevät, kunnes aamun sarastaessa havaitaan toinen lyhytaikainen lisääntyminen ja jälleen pienien hyönteisten ollessa merkittäviä kaiun aiheuttajina.

Vaellusten kannalta tutka kertoo, että päivällä hyönteisiä kulkee ilmakerroksissa jatkuvasti, jolloin osa niistä voi edetä myös hyvin pitkiä matkoja kesäpäivän virtauksissa. Pienien hyönteisten auringonlaskun ja -nousun aikaiset vaellukset kestävät ainoastaan tunnin luokkaa, joten esimerkiksi $10 \mathrm{~m} / \mathrm{s}$ tuulessa ne ehtivät kulkea vain muutaman kymmenen kilometrin päähän. Isojen yöhyönteisten nousu ylemmäksi saattaa merkitä lopulta myös hakeutumista parhaimmin sopivaan lentokorkeuteen. Kesäyö on toki lyhyt, mutta tällaisessa kerroksessa vaellus voi edetä nopeammassa virtauksessa, jolloin esim. $20 \mathrm{~m} / \mathrm{s}$ tuulessa neljässä tunnissa pääsee noin $300 \mathrm{~km}$ päähän. Isojen hyönteisten nopeuden on Dopp- 
ler-tutkalla havaittu myös poikkeavan selvästi tuulesta, joka on voitu mitata läheisistä sadepilvistä tai erillisillä luotauksilla. Tavallista on myös se, että isojen hyönteisten kaiku osoittaa näiden lentoasennon olevan huomattavan yhdensuuntaisen.

Päiväsaikaisissa vaelluksissa tutkat kertovat hyönteisten keskittyvän nauhamaisiin alueisiin, joissa ilma virtaa ylöspäin. Ylöspäin nousevaan ilmaan liittyy alhaalla virtauksen keskittymistä ja siten hyönteisiä yhteen keräävä tuulikenttä. Toisaalta ilman virratessa ylemmäs se jäähtyy ja aiheuttanee virtauksen vastaisen reaktion hyönteisissä, kyse voi olla vain lennon heikentymisestä tai loppumisesta. Tuloksena on hyönteisten kasautuminen nousevan ilman alueille. Rajakerroksen pystyliikkeet myös helpottavat hyönteisten nousua ylemmäs ja usein myös nopeampaan virtaukseen. Muuhun aikaan vuorokaudesta ilmaan nousevat hyönteiset sen sijaan lentävät täysin omin voimin haluamalleen korkeudelle, mikä kertoo myös hyönteisten vaelluskäyttäytymisen erityisluonteesta.

Puolen kilometrin yläpuolella hyönteiset kertyvät usein selvästi suositumpiin kerroksiin. Näissä tapauksissa on havaittu myös eri päivinä eri korkeudella olleiden kerrosten olleen samassa lämpötilassa. Isoja hyönteisiä on havaittu jopa nolla-asteen tuntumassa olevissa ilmakerroksissa. Nämä ovat olleet rajakerroksen ja jopa keskipilvikerroksen yläpuolella. Lentävien yökkösten lämpötilan tiedetäänkin olevan lihastyön johdosta huomattavasti ympäristön lämpötilaa suurempi, näitä on kuvattu lähes tasalämpöisiksi vaelluksellaan. Ritariyökkösen vaellukseen liittyvän kaiun tapauksessa hyönteisten havaittiin jopa nousevan päivällä huomattavasti korkeammalle kuin yöllä, mitä on selitetty Auringon säteilyn aiheuttaman liiallisen lämmityksen välttämisellä.

Erikoisempia havaintoja on alettu tehdä Helsingin yliopiston toisella säätutkalla, jolla mitataan pääasiassa antennin osoittaessa pystysuoraan taivaalle. Tällä tutkalla hyönteiset ovat yleensä havaittavissa kulkemassa yksitellen tutkakeilan läpi 500-3000 m korkeudella. Mittauksissa käytetään tavallisesti $1100 \mathrm{~Hz}$ suurinta mahdollista pulssin toistotaajuutta ja tutkan avulla voidaan mitata kaiun voimakkuuden vaihtelusta isojen hyönteisten siivenlyönnin taajuus sekä myös Doppler-taajuuden perusteella hyönteisen hetkellinen pystynopeus. Näistä tiedoista voidaan tehdä joitakin arvioita vaeltajien lajista, varsinkin kun samaan aikaan Kumpulan tutkalla saadaan muuta tietoa kaikujen aiheuttajista. Tällainen säätutkan käyttö on kuitenkin poikkeuksellista, vaikka se periaatteessa onnistuukin käytössä olevien mittausohjelmien puitteissa.

\section{Polarisaatiosäätutka ja vaellusten ennustaminen}

Polarisaatiosäätutkalla mitattavia ominaisuuksia kaiuista ovat $\mathrm{mm}$. lineaarinen depolarisaatiosuhde vaakapolaroidulla säteilyllä, LDRH, sekä differentiaalinen tutkaheijastuvuustekijä, ZDR. LDRH kertoo, mikä on kaiussa pystypolaroidun säteilyn suhde vaakapolaroituun säteilyyn, kun lähetetty on vaakapolaroitua. Esimerkiksi lähes pallomaisista pisaroista koostuvasta vesisateesta tulevassa kaiussa tämä suure on hyvin pieni, mutta lumisateesta paljon suurempi. ZDR on vaakapolaroituna lähetetyn säteilyn kaiun suhde pystypolaroituna lähetetyn säteilyn kaikuun. Pallomaisista kohteista kaiuilla ei ole eroa, mutta kohteen muodon ollessa pitkulainen kuten hyönteisillä tämä suhde poikkeaa ykkösestä.

POMO-hankkeen aikana vuonna 2007 Kumpulan polarisaatiotutkalla havaittuja hyönteisvaelluksia on tutkittu aikaisempaa järjestelmällisemmin. Tavallinen differentiaalisen tutkaheijastuvuustekijän arvo vastaa Englannissa hyönteistieteellisellä tutkalla havaittua hyönteisten pitkulaisuuden vaikutusta (Chapman ym. 2002). Pelkästään tämän polarisaatio-ominaisuuden perusteella hyönteisiin liittyvä kaiku eroaa selvästi sekä sateisiin, merenpintaan että lintuihin liittyvistä kaiuista. Polarisaatiosäätutkalla hyönteisten vaellusten tunnistaminen sekä erikseen että jopa muiden kaikujen joukosta näyttää olevan hyvin luotettavaa. Muilla säätutkilla tihkusateesta ja runsaasta joukosta pieniä hyönteisiä tulevan kaiun erottaminen toisistaan pelkästään kaiun perusteella on jokseenkin mahdotonta. Siten polarisaatiotutkalla hyönteisten vaelluksen tunnistaminen voidaan tehdä automaattisesti.

Ensimmäinen merkittävä hyönteisvaelluksiin liittynyt havainto Kumpulan uudella tutkalla koski Suomenlahdella havaittua tuomenkehrääjäkoin joukkovaellusta (Mikkola 2006). Tässä tilanteessa, joskin ehkä muiden kuin tuomenkehrääjäkoin kyseessä ollen, kaiun polarisaatio-ominaisuudet poikkesivat merkittävästi tavanomaisesta, erityisesti alueilla, joiden läheisyydessä oli sadekuuroja. Kesällä 2007 on havaittu tilanteita, joissa kaiun ominaisuuksista voitiin päätellä hyönteisten vaelluskäyttäytymisen olleen auringonlaskun aikaan erilaista meren yllä kuin maanpinnan yllä. Lisäksi on havaittu yk- 
sittäisiä isoja hyönteisiä heikon sateen välissä ja jopa sisällä. Tällaiset havainnot ovat toisinaan mahdollisia myös muilla Doppler-säätutkilla.

Vuonna 2007 vaellustilanteet ennustettiin tavanomaisten säänennustemallien avulla hankkeen henkilöiden toimesta ja joidenkin selvitettyjen yleisten vaellusperusteiden mukaan. Näin hyönteisten pyydykset ehdittiin asettamaan paikoilleen ajoissa odottamaan vaelluksia. Käytössä oli useita viirihaaveja 1,5-2 m korkeudella keräämässä tuulen mukana kulkevia hyönteisiä. Viirihaaveja runsaammin ja useammilla paikoilla oli pellon pinnan lähellä keltaisia liima-ansoja. Näiden lisäksi imurysät Viikissä ja Jokioisissa keräsivät tavallisen ohjelman mukaisesti hyönteisiä $12 \mathrm{~m}$ korkeudelta. Merkittävin vaellusjakso joka havaittiin niin tutkilla kuin pyydyksillä oli toukokuun lopulla. Tuhohyönteislajeista pyydyksiin saatuja olivat tuomikirva sekä kaalikoi, jotka tässä vaiheessa olivat selvästi kaukovaeltajia. Yleisimpiä lajeja pyydyksissä keväällä olivat kirvojen ohella kirpat, mutta näiden vaelluskäyttäytymisestä on vielä tehtävä tarkempia tutkimuksia.

Vuoden 1988 kirvojen joukkovaelluksen tarkastelussa käytettiin hyväksi Ilmatieteen laitoksessa laskettuja ilman trajektoreja (Kurppa 1989 ja Nieminen ym. 2000). Trajektori on periaatteessa ilmapaketin ratakäyrä ja tämän määritys tehdään yleensä numeerisen säänennustusmallin avulla laaditun ilmakehän kolmiulotteisen virtauskentän mukaan. Säänennustusmalli on käytännössä täsmällisin käytettävissä oleva menetelmä kertoa ilmakehän tila siitä tehtyjen havaintojen mukaan. Koska käytössä on ennustemalli, niin trajektori voidaan laskea myös tulevaisuuteen. Trajektorin sijasta nykyisin kuitenkin lasketaan leviämisennusteita, jotka käytännössä kertovat myös trajektorien hajonnasta. Radioaktiivisten aineiden ja muiden ilman epäpuhtauksien leviämisennustemallit ovat jo pitkään kuuluneet sääpalvelun työkaluihin.

Hyönteiset kuitenkin poikkeavat leviämismalleissa yleensä käsitellyissä elottomista kohteista sikäli, että ne voivat omilla reaktioillaan merkittävästi vaikuttaa kulkeutumiseensa. Myös hyönteisten lähtö ja laskeutuminen ovat enemmänkin lajin biologiaan kuin ympäristön välittömiin meteorologisiin oloihin liittyviä. Tutkimushankkeessa kootaan tietoja tutkittavien lajien biologiasta sekä varsinkin niiden vaelluskäyttäytymisestä. Tarkoituksena on myös tutkia perusteellisemmin aiemmin todettuja vaelluksia sekä maastohavainnoissa että tutkakaiuissa. Näiden tarkastelujen pohjalta ennustemalliin voidaan sitten rakentaa kullekin vaellukselle ominaisia sääntöjä. POMO-hankkeessa hyönteisvaelluksen ennustamisessa lähtökohdaksi kaavaillaan Ilmatieteen laitoksessa jo käytössä olevaa SILAM-mallia, jota on käytetty myös siitepölyn kaukokulkeutumisen ennustamisessa (Sofiev ym. 2006).

Kaukokartoitustietoja on myös suunniteltu käytettäväksi vaellusten ennustemallissa. Tekokuilla voidaan mitata maanpinnan tilannetta ja etenkin kasvillisuuden kehitys vaikuttaa hyönteisten kantoihin. Pilvisyys on myös yksi satelliiteista mitattu asia, jonka vaikutus voidaan ottaa huomioon niin vaelluksen lähdössä kuin vaelluksen jatkumisessa. Säätutkat kertovat hyönteisten kulusta ja sadealueiden sijainnista, mitä voidaan käyttää hyväksi vaelluksen etenemisen ennusteessa. Doppler-tutkilla mitattava virtaus kertoo hyönteisten osalta jo sinänsä vaelluksen suunnan ja nopeuden, mutta yleensä näiden antamien tietojen pohjalta voidaan myös tarkistaa ennustetta virtauskentästä. Esimerkiksi vuoden 1988 kirvavaelluksessa havaittiin Doppler-säätutkalla mitatun virtauksen olleen merkittävästi trajektorin kertomaa voimakkaampi (Nieminen ym. 2000).

Tarkasteltaviksi lajeiksi on valittu toisaalta tunnettuja maatalouden tuholaisia ja toisaalta perhosia, joiden kaukovaelluksista on olemassa runsaasti kokemuksia ja havaintoja. Vuoden 2008 keväällä on määrä saada toimimaan ennustemallin ensimmäinen kehitelmä. Mallin antamia tuloksia verrataan niin säätutkin kuin pyydyksin saatuihin havaintoihin hyönteisten vaelluksista. Kokemusten perusteella kehitetään käyttöön otettavaksi sopiva ennustemalli.

\section{Kirjallisuus}

Achtemeier, G.L. 1991. The use of insects as tracers for "clear-air" boundary-layer studies by Doppler radar. J. Atm. Oc. Techn. 8: 746-765.

Chapman, J.W., Smith, A.D., Woiwod, I.P., Reynolds, D.R. \& Riley, J.R. 2002. Development of vertical-looking radar technology for monitoring insect migration. Comp. Electr. Agric., 35: 95-110.

Glover, K., Hardy, K., Landry, C. \& Konrad, T. 1966. Radar characteristics of known insects in free flight. Proc. 12th Conf. Radar Meteorol. AMS. 254-258. 
Kurppa, S. 1989. Predicting outbreaks of Rhopalosiphum padi in Finland. Ann. Agric. Fenn. 28: 333347.

Leskinen, M. 1990. Hyönteiset ja säätutkalla mitattava kaiku. Tekninen raportti 7. Meteorologian laitos, Helsingin yliopisto. $32 \mathrm{~s}$.

Leskinen, M. 1998. Hyönteisiä tutkassa. Kirjassa "Suomen Luonto, Selkärangattomat" WSOYyhtymä. 111.

Leskinen, M. 2005. Perhosia tutkassa. Kirjassa "Perhosten lumo - suomalainen perhostieto" (toim. Mikkola, K., Murtosaari, J. \& Nissinen, K.). Kustannusosakeyhtiö Tammi. Hämeenlinna. 156-157.

Mikkola, K. 1996a. Vaelluskatsaus 1994. Baptria. 21(1): 13-16.

Mikkola, K. 1996b. Sää ja hyönteisten vaellukset 1995. Baptria. 21(4): 133-140.

Mikkola, K. 2003. Red admirals Vanessa atalanta (Lepidoptera: Nymphalidae) select northern winds on southward migration. Entolomol. Fenn. 14: 15-24.

Mikkola, K. 2006. Tuomenkehrääjäkoit tulivat pilvinä. Suomen luonto. 65(7): 40-41.

Mikkola, K. \& Leskinen, M. 1998. Hyönteiset. Kirjassa "Suomalainen sääkirja - etanasta El Niñoon (toim. Rinne, J., Koistinen, J. \& Saltikoff, E.). Yhtyneet Kuvalehdet Oy ja Kustannusosakeyhtiö Otava. 161-169.

Nieminen, M, Leskinen, M., Helenius, J., 2000. Doppler radar detection of exceptional massmigration of aphids into Finland. Int. J. Biometeorol. 44: 172-181.

Puhakka, T. \& Saarikivi, P. 1986. Doppler-radar observation of horizontal roll-vortices in Finland. Geophysica. 22: 101-118.

Riley, J.R. 1985. Radar cross section of insects. Proc. IEEE. 73: 228-232.

Schaefer, G.W. 1976. Radar observations of insect flight. Julkaisussa "Insect flight" (toim. Rainey, R.C.). Blackwell Scientific Publications. 75-112.

Sofiev, M., Siljamo, P., Ranta, H. \& Rantio-Lehtimäki, A. 2006. Towards numerical forecasting of long-range air transport of birch pollen: theoretical considerations and a feasibility study. Int. J. Biometeorol. 50: 392-402.

Tiilikkala, K., Vasarainen, A., Koistinen, J. \& Salonoja, M. 1996. Monitoring of the migration of the diamondback moth. Julkaisussa "Remote sensing in agriculture : Reports of the finnish geodetic institute 96:4.Proceedings, NJF Seminar 1996" (toim. Kuittinen, R.). Suomen geodeettisen laitoksen tiedonantoja 96(4): 78-81. 